true birth prevalence in any one country should be similar to the collective prevalence in Europe or even that in the USA.

The number of cases occurring in a given sample varies randomly around the true population prevalence of the condition: the fact that a screening programme for a rare condition has detected as many cases as would be predicted from the population prevalence does not imply that no cases have been missed.

$$
\begin{array}{r}
\text { AMAR SINGH } \\
\text { STUART LOGAN } \\
\text { Epidemiology and Biostatistics Unit, } \\
\text { Institute of Child Health, } \\
\text { 30 Guilford Street, } \\
\text { London WCIN IEN }
\end{array}
$$

1 Pharoah POD, Madden MP. Audit of screening for congenital hypothyroidism. Arch Dis Child 1992; 67: 1073-6.

2 Delange F, Illing R, Rochiccio P, Brock-Jacobsen B. Progress report 1980 on neonatal screening in Europe. Acta Paediatr Scand 1980; 70: 1-2.

\section{Is hearing really assessed after bacterial meningitis?}

EDITOR,-Dr Fortnum and Professor Hull are rightly encouraged by the results of their survey. ' Nearly $90 \%$ of paediatricians claim to refer all children who have suffered from bacterial meningitis for formal hearing assessment. The authors hope that these good intentions are translated into clinical practice.

Unfortunately this may not be the case. A recent review of bacterial meningitis at our hospital shows that $31 \%$ of survivors had no documented hearing test.

Casenotes of children admitted with bacterial meningitis over the eight years 1984 to 1992 were reviewed. Of the 206 identified 156 were available, excluding tertiary referrals. Of these five children died, and $12(8 \%$ of survivors) were later found to have hearing loss. In 49 casenotes (31\%) there was no evidence that a formal hearing test had been carried out. Of these six children were not offered any follow up, 11 did not attend follow up, and two moved to other health districts and were lost to follow up. The remaining 30 (19\% of survivors) were seen as outpatients, but had no documented hearing test result.

There was no significant difference in the proportion of children with no hearing test recorded between the first four years of the study period, and the later four years (not significant by $\chi^{2}$ ). There was also no trend suggesting recent improvement evident over time.

Who should ensure a formal hearing test is performed on children who have had bacterial meningitis? Improved communication between hospital and community services is required. The introduction of an integrated child health service could prove valuable in this respect.

$$
\begin{array}{r}
\text { F A I RIORDAN } \\
\text { A P J THOMSON } \\
\text { Institute of Child Health, } \\
\text { Roval Liverpool Children's Hospital (Alder Hey), } \\
\text { Eaton Road, } \\
\text { Liverpol L12 } 2 \mathrm{AP}
\end{array}
$$

1 Fortnum HM, Hull D. Is hearing assessed after bacterial meningitis? Arch Dis Child 1992; 67: $1111-2$.

Near fatal haemorrhage from the superior sagittal sinus in Adams-Oliver syndrome

EDITOR,-We wish to emphasise the danger of

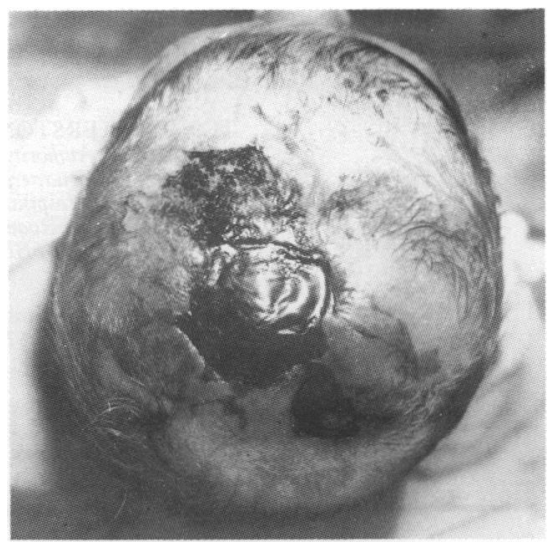

Figure 1 Scalp appearance at birth: note eschar.

haemorrhage from the superior sagittal sinus in association with aplasia cutis congenita of the scalp where there is also a skull defect.

\section{Case report}

A boy was born at full term after intrauterine growth retardation had been noted on antenatal ultrasonography. The parents were nonconsanguinous and there was no history of maternal drug ingestion. Birth weight was $2080 \mathrm{~g}$ with head circumference of $30.2 \mathrm{~cm}$ (below the 3rd centile).

There was a large $(4 \times 4 \mathrm{~cm})$ area of scalp aplasia with underlying bony deficit (fig 1 ). The infant also had rudimentary toes and a short left index finger. A diagnosis of Adams-Oliver syndrome was made, and his mother and grandfather were found to have features of the syndrome, which is usually transmitted in an autosomal dominant manner.

The child initially progressed well, but was admitted at age 3 weeks with bleeding from the scalp. When a dressing was removed the eschar ruptured and there was torrential haemorrhage from the superior sagittal sinus, requiring immediate resuscitation. Subsequently, an area of exposed brain $1.5 \mathrm{~cm}$ in diameter was noted, with free drainage of cerebrospinal fluid.

A combined neurosurgical and plastics procedure debrided, defined and closed the defect, employing a rotation scalp flap and split skin graft (fig 2). Postoperatively an initial cerebrospinal fluid leakage stopped spontaneously, and prophylactic antibiotics were given for several weeks. His subsequent progress has been uneventful.

\section{Discussion}

Scalp/skull defects may be an isolated phenomenon or associated with Adams-Oliver syndrome.' Twenty per cent of isolated scalp

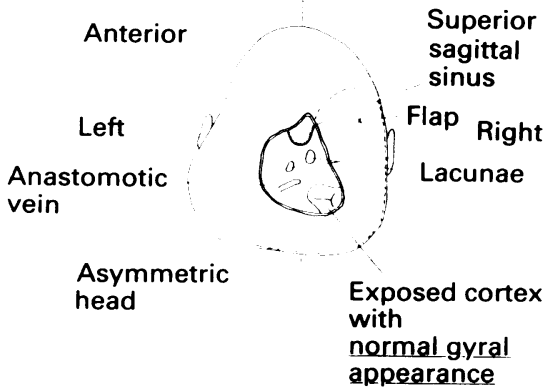

Figure 2 Schematic representation of operative findings. defects have an underlying skull defect, whereas in Adams-Oliver syndrome $75 \%$ have scalp involvement and $64 \%$ of children have skull defects. ${ }^{2+}$ The complications (infection, bleeding) and management (early closure in cases where the superior sagittal sinus is vulnerable) are similar in both situations.

Neonatal paediatricians should be aware of the potentially life threatening situation when scalp aplasia, underlying skull defect, and secondary infection occur in infants with Adams-Oliver syndrome. Successful closure of the cranial defect can be achieved and a combined neurosurgical and plastics approach is advocated.

P M DAVIS Community Health Unit Lansdowne Hospital, Lansdowne Hospital,
Canton, Cardiff CFI $8 U L$

P W BUSS

P W BUSS
Department of Medical Genetics, University Hospital of Wales, Cardiff CF 4 4XW

B A SIMPSON Department of Neurosurgery, University of Wales, Cardiff CF 4 XW

P J SYKES

Department of Plastic Surgery, St Lawrence Hospital,

Adams FH, Oliver P. Hereditary deformities in man due to arrested development. $\mathcal{F}$ Hered 1945 36: 3-7.

2 Stevenson RE, DeLoache WR. Aplasia cutis congenita of the scalp. Proceedings of the Greenwood Genetics Center 1988; 7: 14-8.

3 Whitley $\mathrm{CB}$, Gorlin RJ. Adams Oliver syndrome revisited. Am F Med Genet 1991; 40: 319-26.

4 Toriello HV Graf RG, Florentine MF, Lacina oriello HV, Graff RG, Florentine MF, Lacina S Moore WD. Scalp and limb defects with cutis marmorata telangiectatica congenita: AdamsOliver syndrome? Am $\mathcal{F}$ Med Genet 1988; 29:

\section{Rett syndrome and the 4th metatarsal}

EDITOR,-Rett syndrome,' an intellectually handicapping, probably genetic disorder affects around one in 10000 females $^{2}$ and is remarkable for the absence of coexisting injury, disease or dysmorphism. As early as 1985 , one of us (AMK) observed isolated shortening of the 4th metatarsal in some affected girls but not their families.

The British Isles Survey for Rett Syndrome and clinics organised by the UK Rett Syndrome Association have recently provided an opportunity for serial examinations of cases. Among the last 50 classic cases aged over 5 years, we have observed nine with this solitary anomaly ( 1 in 5-6 cases). It was not observed in family members. Both feet were usually affected.

We are now examining residents and staff at the Royal Scottish National Hospital (Mental Handicap) as well as further consecutive cases of Rett syndrome and their families to compare prevalence in these groups.

Several disorders involving widespread malformations may include shortening of the 4th metatarsal and an increased incidence of minor malformations is generally expected among the intellectually handicapped population. Ray and Haldane in 1965 observed this solitary abnormality in three out of 2500 in a general male population. From their study of 61 pedigrees, they proposed dominant inheritance with $27 \%$ penetrance.

Expression of a local growth anomaly migh be attributed to the general growth disorder or to hyperventilation (usual in Rett syndrome and associated with reduced peripheral circula- 